\title{
Improvement of Fatigue Limit by Shot Peening for High-Strength Steel Containing a Crack-like Surface Defect
}

\author{
Koji TAKAHASHI a, Toshihiko AMANO a, \\ Kotoji ANDO a and Fumio TAKAHASHI ${ }^{b}$
}

a Faculty of Engineering, Yokohama National University, 79-5, Tokiwadai, Hodogaya, Yokohama, 240-8501, Japan

b NHK Spring Co. Ltd, 3-10, Fukuura, Kanazawa, Yokohama, 236-0004, Japan

\section{Correspondence:}

Dr. Koji Takahashi

Associate Professor

Faculty of Engineering,

Yokohama National University,

79-5, Tokiwadai, Hodogaya, Yokohama, 240-8501, Japan.

E-mail:ktaka@ynu.ac.jp 


\title{
Improvement of Fatigue Limit by Shot Peening for High-Strength Steel Containing a Crack-like Surface Defect
}

\begin{abstract}
Effects of shot peening on the bending fatigue limit of high-strength steel containing an artificial semi-circular slit were investigated. Shot peening (SP) and stress shot peening (SSP) were conducted on the specimens containing an artificial semi-circular slit with a depth of $a=0.1,0.2$ and $0.3 \mathrm{~mm}$. Then, bending fatigue tests were conducted on the specimens. The fatigue limit was improved by SP and SSP. In the case of SP and SSP specimens, the specimens with a semi-circular slit under $a=0.2 \mathrm{~mm}$ fractured outside the slit, and they had considerably high fatigue limits. Therefore, a semi-circular slit with a depth of under $a=$ $0.2 \mathrm{~mm}$ could be rendered harmless by SP or SSP. We found that the fatigue limit of specimens with a semi-circular slit that received SP or SSP was determined by the threshold condition for non-propagation of fatigue cracks that emanated from outside the slit. Whether the semi-circular slit is rendered harmless or not is decided by the relationship between the stress intensity factor range of semi-circular cracks and the threshold stress intensity factor range.
\end{abstract}

\section{KEY WORDS}

Shot peening, Fatigue strength, High-strength steel, Crack-like surface defect, Residual stress, Fracture mechanics

\section{INTRODUCTION}

Lighter-weight mechanical parts are increasingly sought after from the perspectives of energy-saving and environmental issues; thus, the demand for improved fatigue limits of these parts is also increasing. In general, increasing the hardness and the introduction of compressive residual stresses are effective methods for improving fatigue limits. While a hardness increase is known to increase the sensitivity of the material to defects, introducing compressive residual stresses by shot peening (SP) is widely used to improve the fatigue limits of vehicle parts (Suresh, 1991; Mitsubayashi et al., 1995; Ishigami, et al., 2000,Webster, et al., 2001; Guaglian., et al., 2002; Lang, et al., 2003).

Surface defects arising during the manufacturing process may be present in structural parts. If these defects can be rendered harmless and the fatigue limits of such material improved through SP, marked improvement in component reliability and a decrease in costs can be achieved. Only a few studies have investigated the fatigue limits of materials containing surface defects after conducting SP (Kuwahara et al.2004; Masaki et al., 2006). In one study, the effects of SP on fatigue limit improvements were investigated in high-strength steel containing an initial defect introduced by Vickers indentation (Kuwahara et al.2004).

In recent years, it has been clarified that SP on high-strength steel containing artificial micro-holes leads to considerable improvements in fatigue limits while increasing the critical defect size; in other words, it is possible to render surface defects harmless (K. Takahashi et al., 2007). However, there are very few examples of evaluations of fatigue limits after SP in materials containing crack-like surface defects (F. Takahashi et al., 2008). 
In the present study, we conducted plane bending fatigue tests of high-strength steel that had undergone SP and stress shot peening (SSP) after the introduction of semi-circular slits of various dimensions into the surface. This enabled us to evaluate the efficacy of SP and SSP for improving the fatigue limits of high-strength steel with crack-like surface defects. Furthermore, we conducted a fracture mechanics evaluation of the dimensions of such defects that can be rendered harmless by SP and SSP.

\section{EXPERIMENTAL PROCEDURES}

\subsection{Test material and specimen}

The test material used in this study was spring steel, Japanese Industrial Standards (JIS) SUP9A. Table 1 shows the chemical composition of the material. Figure 1 shows the plane-bending fatigue test specimen used in the present study. The thickness and minimum width of the specimen were $3 \mathrm{~mm}$ and 10 $\mathrm{mm}$, respectively. Figure 2 shows the manufacturing procedure of the test specimen. The surface of the specimen was machined by grinding. On one side of the specimen, an artificial semi-circular slit, shown in Fig. 3, was introduced by electric discharge machining to simulate an initial crack-like surface defect. The depth of the semi-circular slit was $a=0.1,0.2$ and $0.3 \mathrm{~mm}$. Next, the specimens were oil-quenched at 860 ${ }^{\circ} \mathrm{C}$ and tempered at $460^{\circ} \mathrm{C}$. The Vickers hardness (HV) of the specimens after heat treatment was $470 \mathrm{HV}$.

\subsection{SP condition}

After heat treatment, we conducted SP or SSP on slit and non-slit specimens with a direct pressure peening system. The SP conditions adopted were: $0.62 \mathrm{MPa}$ air pressure, $0.67 \mathrm{~mm}$ shot diameter, $600 \mathrm{HV}$ shot hardness, $40 \mathrm{~s}$ shot time, $300 \%$ coverage at specimens surface and $0.496 \mathrm{mmA}$ arc height. In SSP, a four-point bending system was used to apply tensile stress. The tensile stress on the surface was measured using a strain gage. The tensile stress applied to the specimens was $1250 \mathrm{MPa}$.

\subsection{Distribution of residual stress}

The residual stress distributions for samples with no SP (Un-SP), SP and SSP are shown in Fig. 4. Residual stress measurements were performed by the X-ray diffraction method. The X-ray conditions are: $\mathrm{Cr}-\mathrm{K} \alpha$ beam X-ray spectrum and $2.0 \mathrm{~mm} \mathrm{X-ray} \mathrm{beam} \mathrm{injection} \mathrm{diameter.} \mathrm{The} \mathrm{residual} \mathrm{stress} \mathrm{distributions}$ near the semi-circular slit were important. However, it is difficult to measure the residual stress near the semi-circular slit in this experiment due to a limitation of beam injection diameter. Thus, the residual stress distributions outside a semi-circular slit were measured. The residual stress distributions in the thickness direction were obtained by alternately measuring the residual stress on the surface and then chemically etching to remove the surface layer. The residual stress data in Fig. 4 were corrected for the relief resulting from removing the layers. In the case of Un-SP specimens, the residual stress was approximately zero. In the case of SP and SSP specimens, the surface compressive residual stress was approximately $550 \mathrm{MPa}$ and $810 \mathrm{MPa}$, respectively. The compressive residual stresses were remarkably increased by SSP (Müller, 1993; Okada, et al., 2004).

\subsection{Surface roughness}


The surface roughness for Un-SP, SP and SSP specimens is shown in Table 2. The value of surface roughness increased after SP and SSP. However, the values of surface roughness were much smaller than the depth of the semi-circular slit $(0.1-0.3 \mathrm{~mm})$.

\subsection{Fatigue tests}

Fatigue tests were carried out on all specimens using a plane-bending fatigue testing machine. The fatigue test conditions were a stress ratio of $R=0$ and a cyclic frequency of $20 \mathrm{~Hz}$. The stress waveform was a sine wave. The fatigue limit was defined as the maximum stress amplitude under which the specimen endured $10^{7}$ cycles. The fracture surface was observed using a scanning electron microscope (SEM).

\section{EXPERIMENTAL RESULTS AND DISCUSSION}

\subsection{Fatigue test results}

Figures 5(a) to 5(d) show the relationship between the stress amplitude and the number of cycles to failure. The symbol indicates Un-SP specimens. The symbols $\boldsymbol{\square}$ and $\boldsymbol{\Delta}$ indicate SP and SSP specimens, respectively. The asterisk symbols indicate that the specimen fractured outside the semi-circular slit. The arrow indicates that the fracture had not occurred when the test was terminated at $10^{7}$ cycles. The values of the fatigue limit are indicated in Figs. 5(a) to 5(d). By SP and SSP, the fatigue limit and the fatigue life of the specimens increased.

Figure 6 shows the increasing ratio of the fatigue limit for each specimen. The fatigue limit increased 9-157\% for SP specimens and 41-329\% for SSP specimens compared to Un-SP specimens. The increasing ratio of fatigue limit for SSP specimens with $\mathrm{a}=0.3 \mathrm{~mm}$ slit was $329 \%$. This increasing ratio was quite high. The reason for this is discussed in section 3.5

\subsection{Size of the semi-circular slit that can be rendered harmless by SP and SSP}

Figure 7 shows the results of the bending fatigue tests, which show the relationship between the stress amplitude and the depth of the semi-circular slit. The solid symbols represent the specimens fractured during fatigue tests. The open symbols represent the specimens that did not fracture up to $10^{7}$ cycles. The broken lines in Fig. 7 represent the fatigue limit.

The asterisk symbols indicate that the specimen fractured outside the semi-circular slit. Among the SP and SSP specimens, all specimens fractured outside the semi-circular slit except one SSP specimen with a slit of $a=0.2 \mathrm{~mm}$. Therefore, the fatigue limits of SP and SSP specimens with a slit of $a=0.1 \mathrm{~mm}$ and $0.2 \mathrm{~mm}$ are equivalent to those of SP and SSP specimens without a semi-circular slit. In SP and SSP specimens with a slit of $a=0.3 \mathrm{~mm}$, although strength reduction rates in contrast to Un-SP specimens are small, all specimens fractured from the semi-circular slit. Therefore, we found that a semi-circular slit under $a=0.2 \mathrm{~mm}$ could be rendered harmless by SP or SSP.

\subsection{Fracture surface}

Figure 8 shows SEM images of fracture surfaces of specimens having a semi-circular slit. In Un-SP specimens, the specimens fractured from the semi-circular slit regardless of the depth of the slit. On the other hand, the SP and SSP specimens with a slit of $a=0.1$ and $0.2 \mathrm{~mm}$ fractured outside the slit. As a 
result, a surface slit with a depth under $a=0.2 \mathrm{~mm}$ could be rendered harmless by SP. On the other hand, SP and SSP specimens with a slit of $a=0.3 \mathrm{~mm}$ fractured from the slit.

The shot did not hit inside the slit during peening process because average diameter of the shot $(0.67 \mathrm{~mm})$ was much larger than the width of the slit $(0.03 \mathrm{~mm})$. Thus, the surface slits were not so deformed by SP or SSP except in the surface area where the shots made contact, as shown in Fig. 8(h) and (i). Thus, the compressive residual stresses are the main reason for increasing the fatigue limit.

\subsection{Non-propagating cracks}

Defects smaller than critical size are acceptable or non-damaging to the fatigue limit of metals, and the critical size is smaller for metals having a higher static strength. In this study, we found that a surface slit under $0.2 \mathrm{~mm}$ in depth was rendered harmless by SP and SSP. To determine the reason for this, we had to investigate the size of non-propagating cracks. It is difficult to determine a non-propagating crack size by surface observation due to the surface roughness after shot peening. Thus, the specimens tested under the fatigue limit were heat-treated at $280{ }^{\circ} \mathrm{C}$ in air to produce a heat tint color at the crack surface. Then, they were compulsory-fractured under excessive cyclic loading.

Several non-propagating cracks were observed on the fracture surfaces of specimens. All nonpropagating cracks emanated from outside the surface slit in specimens with a slit under $a=0.2 \mathrm{~mm}$. Figure 9 shows the fracture surface of a SP specimen with a slit of $a=0.1 \mathrm{~mm}$. Figure 9(a) shows the macroscopic fracture surface observed by an optical microscope. Figures 9(b) to (f) show a higher magnification of the non-propagation cracks observed by SEM. Non-propagating cracks approximately $0.16 \mathrm{~mm}$ in maximum depth existed without causing a specimen fracture. The reason for this is that compressive residual stress decreases the stress intensity factors at the crack tip. We found that the fatigue limit of specimens having a semi-circular slit that received SP or SSP determined by the threshold condition for non-propagation of fatigue cracks emanated from outside the slit.

\subsection{Improvement of fatigue strength by the overloading effect for a specimen with a surface slit}

As mentioned in section 3.1, the increasing ratio of fatigue limit for SSP specimens with $a=0.3 \mathrm{~mm}$ slit was quite high. To determine the reason, we conducted the following fatigue tests using a specimens with a slit of $a=0.3 \mathrm{~mm}$. The slit area was subjected to tensile stress of $1250 \mathrm{MPa}$ by a four-point bending system. The tensile stress was the same as that used for SSP, but shot peening was not conducted in this case. The symbols $\diamond$ in Fig. 5(d) show the results of fatigue tests for specimens subjected to a tensile overload. As a result, the fatigue limit was increased $71 \%$ by tensile overloading. It was pointed out by Mizukami et al. (2010) that compressive residual stresses were formed in the vicinity of the surface slit after tensile overloading. Thus, the fatigue limits were increased after tensile overloading. This experimental result suggested that the increasing of the fatigue limit by SSP was caused by both (a) compressive residual stress caused by shot peening process, and (b) compressive residual stress at the vicinity of a slit caused by tensile stress.

\subsection{Evaluation of the defect size rendered harmless by SP and SSP based on fracture mechanics}

The defect size rendered harmless by SP was evaluated based on fracture mechanics assuming that the semi-circular slit was equivalent to a semi-circular crack. In this study, we used the following equation 
to evaluate the apparent stress intensity factor range, $\Delta K_{T}$, assuming that the positive value of the stress intensity factor contributes to fatigue crack propagation:

$$
\Delta K_{T}=K_{\max }+K_{R}
$$

where $K_{\max }$ is the stress intensity factor by maximum tensile stress and evaluated by Newman -Raju's equation (Newman and Raju, 1981). We used the maximum applied stress, $\sigma_{\max }$, corresponding to the fatigue limits of SP and SSP non-slit specimens when we evaluated $K_{\max }$, i.e. $\sigma_{\max }=960 \mathrm{MPa}$ for SP specimens and $\sigma_{\max }=1240 \mathrm{MPa}$ for SSP specimens. $K_{R}$ is the stress intensity factor by residual stress. For the analysis of the stress intensity factor for surface cracks subjected to arbitrarily distributed surface stress, the equations of API RP579 (American Petroleum Institute, 2000) were used to calculate $K_{R}$. The stress intensity factor for a semi-elliptical crack in finite plate is expressed as follows :

$$
\begin{gathered}
K_{R}=\left[G_{0} \sigma_{0}+G_{1} \sigma_{1}\left(\frac{a}{t}\right)+G_{2} \sigma_{2}\left(\frac{a}{t}\right)^{2}\right. \\
\left.\quad+G_{3} \sigma_{3}\left(\frac{a}{t}\right)^{3}+G_{4} \sigma_{4}\left(\frac{a}{t}\right)^{4}\right] \sqrt{\frac{\pi a}{Q}} f_{w} \\
Q=1.0+1.464\left(\frac{a}{c}\right)^{1.65} \\
f_{w}=\left\{\sec \left(\frac{\pi c}{2 W} \sqrt{\frac{a}{t}}\right)\right\}^{0.5}
\end{gathered}
$$

where $G_{0}$ to $G_{4}$ are the influence coefficients for a semi-elliptical surface crack and provided in API RP579, and $a$ and $c$ are the depth and half length of a semi-elliptical surface crack, respectively. $W$ and $t$ are the width and thickness of a plate, and $\sigma_{0}$ to $\sigma_{4}$ are coefficients obtained by curve fitting the residual stress distribution in the fourth-order polynomial distribution, as shown by the following equation:

$$
\sigma(x)=\sigma_{0}+\sigma_{1}\left(\frac{x}{t}\right)+\sigma_{2}\left(\frac{x}{t}\right)^{2}+\sigma_{3}\left(\frac{x}{t}\right)^{3}+\sigma_{4}\left(\frac{x}{t}\right)^{4}
$$

where $x$ shows the distance from the surface in the depth direction. In this study, the residual stress distributions in SP and SSP specimens (Fig. 4) were approximated in the fourth-order polynomial distribution. We have carried out preliminary study on the stability of compressive residual stress. We confirmed that the relaxation of compressive residual stress was negligible in the test condition mentioned in section 2.3. Thus, the residual stress distributions measured before fatigue tests shown in Fig.4 were used.

Figure 10(a) and (b) show the relationship between the apparent stress intensity factor range, $\Delta K_{T}$, and crack depth $a . \Delta K_{T, A}$ and $\Delta K_{T, C}$ represent $\Delta K_{T}$ at the deepest point and at the surface of a crack, respectively. The threshold stress intensity factor range, $\Delta K_{t h}$, depends on the crack size. Several equations to determine the relationship between $\Delta K_{t h}$ and crack length have been proposed. In this study we used the 
equation proposed by El Haddad et al. (1979), because the equation was successfully applied to predict the $\Delta K_{\text {th }}$ of a spring steel, as follows:

$$
\Delta K_{\text {th }}=\left\{\left(\frac{1}{\Delta K(L)_{t h}}\right)^{2}+\left(\frac{1}{\alpha \Delta \sigma_{w 0} \sqrt{\pi a}}\right)^{2}\right\}^{-1 / 2}
$$

where $\Delta K(L)_{t h}$ is the threshold stress intensity factor range $\Delta K_{t h}$ for a large crack. We used $\Delta K(L)_{t h}=7.5$ $\mathrm{MPa} \cdot \mathrm{m}^{1 / 2}$ obtained by the $\Delta K$ decreasing fatigue test for a compact tension specimen of SUP9A. $\Delta \sigma_{w 0}$ is a stress range at the fatigue limit for a non-slit specimen. We used $\Delta \sigma_{w 0}=880 \mathrm{MPa}$, obtained in a fatigue test. Here, $a$ is the depth of a surface crack, and $\alpha$ is a shape parameter obtained by Newman-Raju's equations.

Assuming that the semi-circular slit was equivalent to a semi-circular crack, we can judge whether the semi-circular slit was rendered harmless. If $\Delta K_{T}$ is smaller than $\Delta K_{t h}$, we judged the surface crack to have been rendered harmless. Thus, the intersection between $\Delta K_{T}$ and $\Delta K_{\text {th }}$ gives the defect size $a_{\max }$ that can be rendered harmless. The defect size $a_{\max }$ for SP and SSP specimens was $0.24 \mathrm{~mm}$ and $0.27 \mathrm{~mm}$, respectively. As mentioned in section 3.2, a semi-circular slit with $a=0.2 \mathrm{~mm}$ was rendered harmless by SP and SSP; however a slit with $a=0.3 \mathrm{~mm}$ was not. The prediction results were consistent with the experimental results. Thus, the defect size rendered harmless by SP and SSP can be successfully predicted in spite of the difference in residual stress distribution.

\section{CONCLUSION}

(1) The fatigue limit of spring steel specimens containing a semi-circular slit was increased by SP and SSP. The fatigue limits increased $130 \%-157 \%$ for SP specimens and $210 \%-329 \%$ for SSP specimens in contrast to Un-SP specimens.

(2) The specimens having a semi-circular slit with a depth of $a=0.2 \mathrm{~mm}$ subjected to SP and SSP fractured outside the slit and had very high fatigue limits, almost equal to those of the non-slit SP specimens. For this reason, we conclude that a semi-circular slit under $0.2 \mathrm{~mm}$ in depth can be rendered harmless by SP or SSP.

(3) The fatigue limit of the specimens having a semi-circular slit with a depth under $0.2 \mathrm{~mm}$ subjected to SP or SSP was determined by the threshold condition for the non-propagation of fatigue cracks emanating from outside the slit. This is why a semi-circular slit with a depth under $0.2 \mathrm{~mm}$ was made acceptable by SP.

(4) The defect size rendered harmless by SP and SSP was evaluated based on fracture mechanics assuming that the semi-circular slit was equivalent to a semi-circular crack. We judged that a surface crack was rendered harmless if the apparent fracture toughness range, $\Delta K_{T}$, was smaller than the threshold stress intensity factor range, $\Delta K_{t h}$. The prediction results were consistent with the experimental results. Thus, the defect size rendered harmless by SP or SSP can be successfully predicted independent of residual stress distribution.

\section{REFERENCES}

Suresh, S. (1991), Fatigue of Materials, Cambridge University Press, Cambridge, pp.134-135. 
Mitsubayashi, M., Miyata, T. and Aihara, H. (1995), "Prediction of improvement in fatigue strength by shot peening and selection of most effective peening condition", Transactions of the Japan Society of Mechanical Engineers. Ser. A, Vol. 61, No. 586, pp. 1172-1178.

Ishigami, H., Matsui, K., Jin, Y. and Ando, K. (2000), "A study on stress, reflection and double shot peening to increase compressive residual stress", Fatigue Fract. Eng. Mat. Struct. Vol. 23, pp. 959-963.

Webster, G.A and Ezeilo, A. N. (2001), "Residual stress distributions and their influence on fatigue lifetimes", International Journal of Fatigue, Vol. 23, pp. 375-383.

Guagliano M., and Vergani L. (2002), "An approach for prediction of fatigue strength of shot peened components.", Engineering Fracture Mechanics., Vol.71, pp. 501-512.

Lang, K. H., Schulze, V. and Vohringer, O. (2003), "Shot peening and fatigue strength of steels", Wagner, L. (Ed.), Shot peening, Wiley-Vch, Weinheim, pp. 281-294.

Kuwahara, M., Saruki, K., Kondo S. and Mano, H. (2004), "Improvement of fatigue strength spring wire steel having dent defect", in Technical Report of Japan Society Spring Engineers Meeting in November 2004 in Nagoya, Japan, Japan Society Spring Engineers, pp. 1-4.

Masaki, K., Ochi, Y., Kumagai, Y., Matsumura, T., Sano Y. and Naito, H. (2006), "Influence of laser peening treatment on high-cycle fatigue properties of degassing processed $\mathrm{AC} 4 \mathrm{CH}$ aluminum alloy", Journal of the Society of Materials Science, Japan, Vol. 55, No. 7, pp. 706-711.

Takahashi, K., Amano, T., Miyamoto, T., Ando, K., Takahashi, F., Tange, A., Okada H. and Ono, Y., (2007), "Improvement of fatigue strength by shot peening for spring steel specimens containing an artificial surface defect", Transactions of Japan Society of Spring Engineers, No. 52, pp. 9-13.

Takahashi, F., Tange A. and Ando, K. (2008), "Effect of shot peening on fatigue limit of surface flawed samples", Fatigue Fract. Eng. Mater. Struct. Vol. 31, pp. 242-250.

E. Müller (1993), "Some aspects of stress peening of coil springs for vehicle suspensions", in Proceedings of the 5th Int. Conf. on Shot Peening, Coventry University, Oxford, pp. 341-348

Okada, H., Tange, A., Tango, K. and Ando, K. (2004), "Effect of pre-stress on stress shot peening", Transactions of the Japan Society of Mechanical Engineers, Ser. A, Vol. 70, No. 692, pp. 647653.

Mizukami, H., Hanaori, K., Takahashi, K., Tange, A and Ando, K. (2010), "Improvement Fatigue Limit of Steel Containing a Small Crack-Like Surface Defect by Overload Effect”, International Journal of Structural Integrity, 1-2, p.153-160.

Newman, J.C Jr. and Raju, I.S. (1981), “An empirical stress-intensity factor equation for the surface crack”, Eng. Fract. Mech. Vol. 15, pp. 185-102.

American Petroleum Institute, (2000), Recommended practice 579, fitness for service, American Petroleum Institute., pp. C3-C10.

El Haddad, M.H., Topper, T.H. and Smith, K.N. (1979), "Prediction of non propagating cracks", Eng. Fract. Mech., Vol. 11, pp. 573-584. 


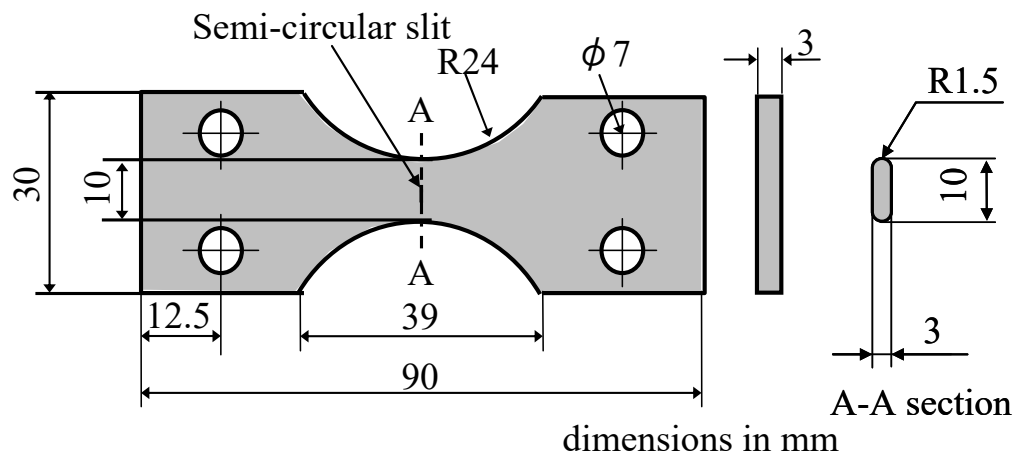

Fig.1 Shape and dimension of specimen.

\begin{tabular}{|c|c|c|c|c|}
\hline \multirow{6}{*}{$\begin{array}{c}\text { Machining } \\
\text { Fig. } 1\end{array}$} & \multirow{2}{*}{$\begin{array}{c}a=0.1,0.2,0.3 \mathrm{~mm} \\
\text { Fig. } 3\end{array}$} & \multirow{2}{*}{$\begin{array}{c}\text { Vacuum quenching } \\
\left(860^{\circ} \mathrm{C} \times 45 \mathrm{~min}\right)\end{array}$} & & $a=0.1,0.2,0.3 \mathrm{~mm}$ \\
\hline & & & Shot peening & $a=0.1,0.2,0.3 \mathrm{~mm}+\mathrm{SP}$ \\
\hline & & & 4 Stress shot peening & $a=0.1,0.2,0.3 \mathrm{~mm}+\mathrm{SSP}$ \\
\hline & & & & Smooth \\
\hline & & $\begin{array}{c}\text { Tempering } \\
\left(460^{\circ} \mathrm{C} \times 60 \mathrm{~min}\right)\end{array}$ & Shot peening & Smooth + SP \\
\hline & & & Stress shot peening & Smooth + SSP \\
\hline
\end{tabular}

Fig.2 Flowchart of specimen machining process.

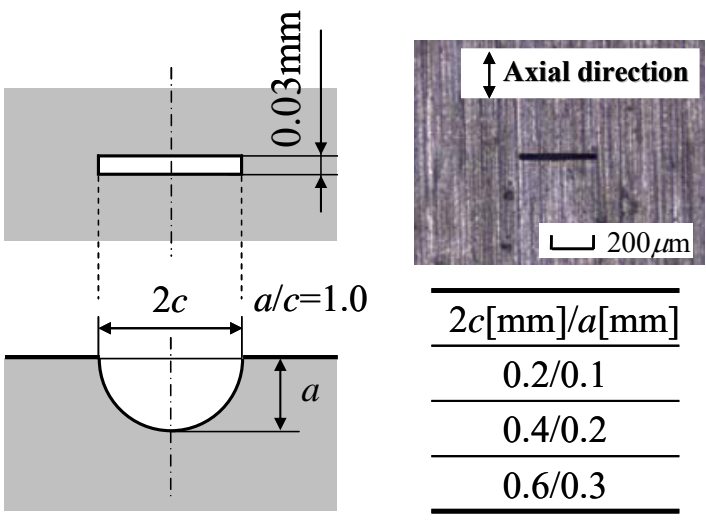

Fig.3 Shape and dimension of semi-circular slit. 


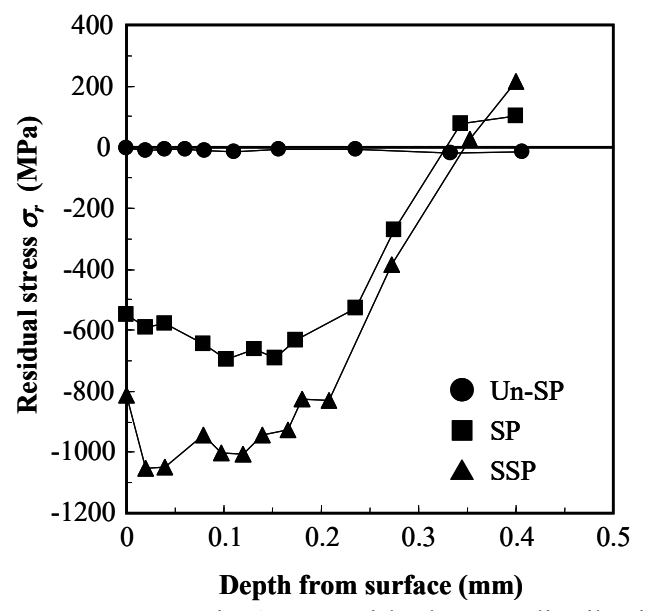

Fig.4 Residual stress distribution.

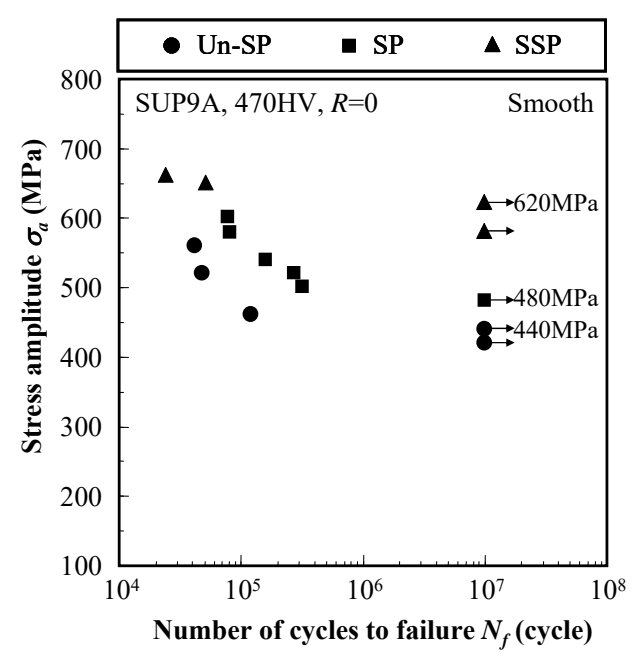

(a) Smooth

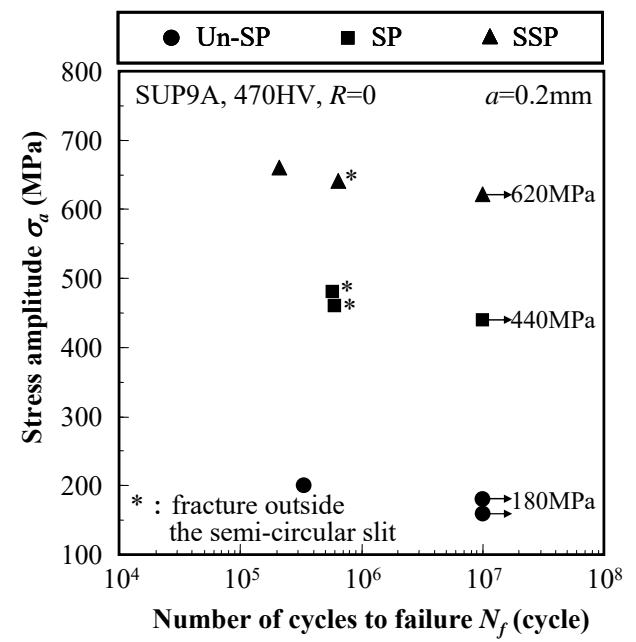

(c) $a=0.2 \mathrm{~mm}$

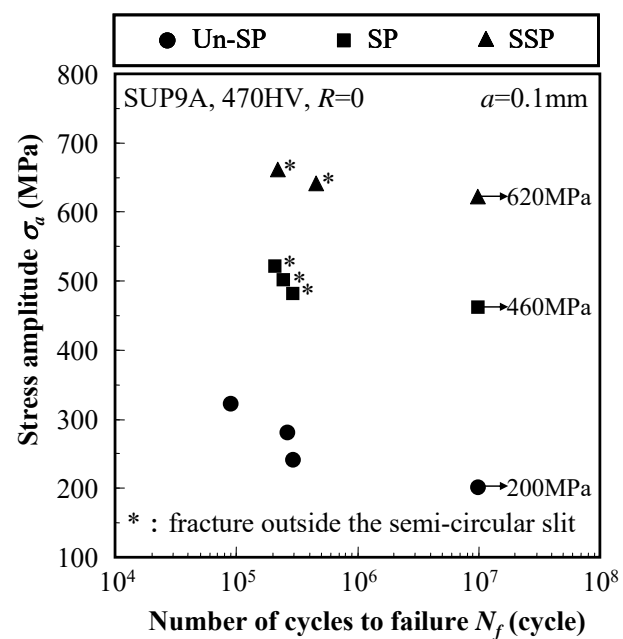

(b) $a=0.1 \mathrm{~mm}$

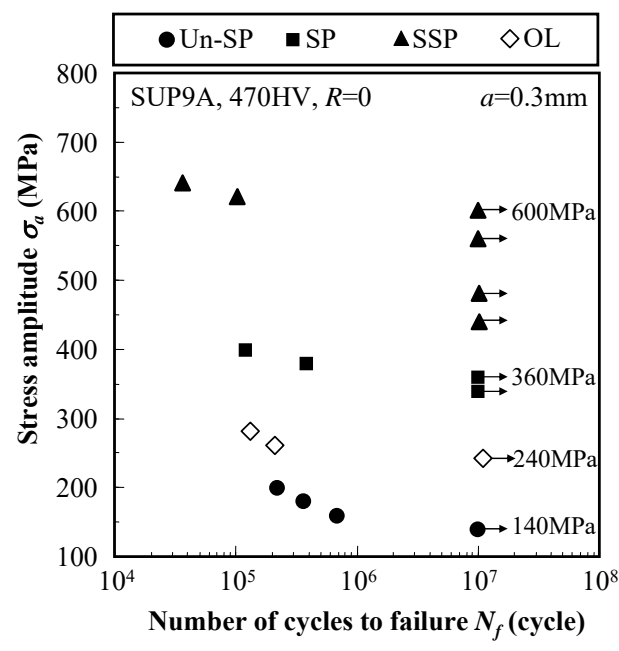

(d) $a=0.3 \mathrm{~mm}$

Fig. $5 \mathrm{~S}-\mathrm{N}$ curve for plane bending fatigue test (SUP9A, $470 \mathrm{HV}, R=0$ ). 


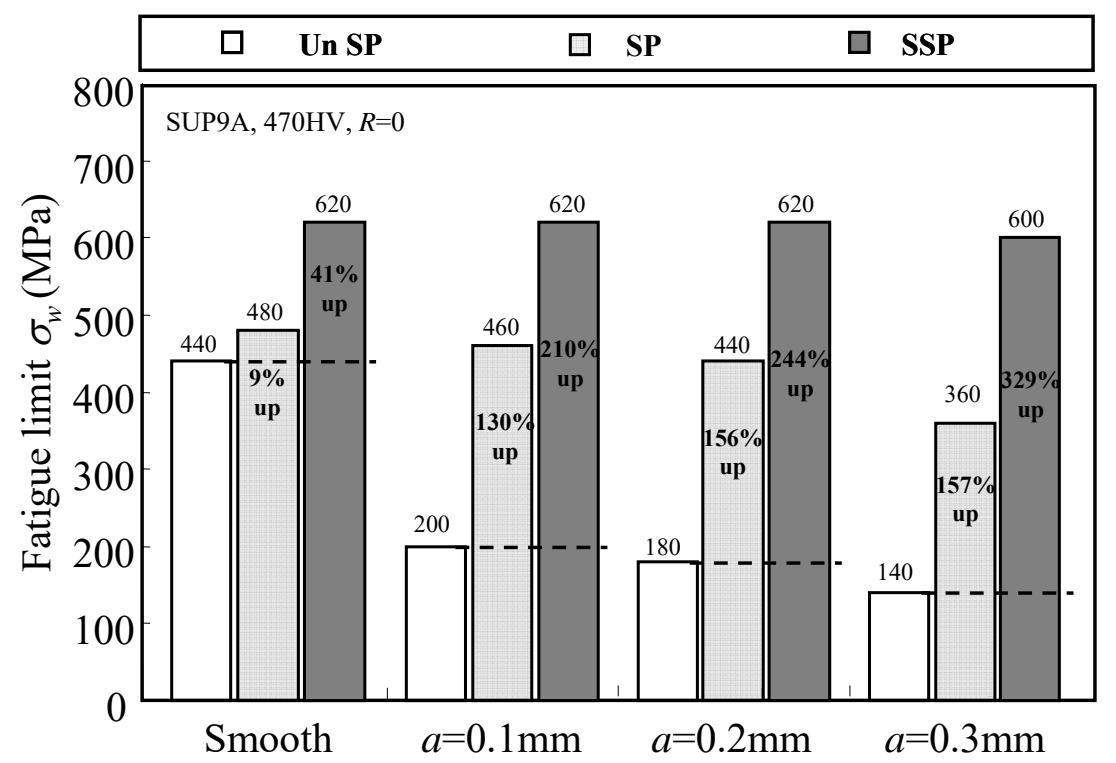

Fig. 6 Improvement ratio of fatigue limit.

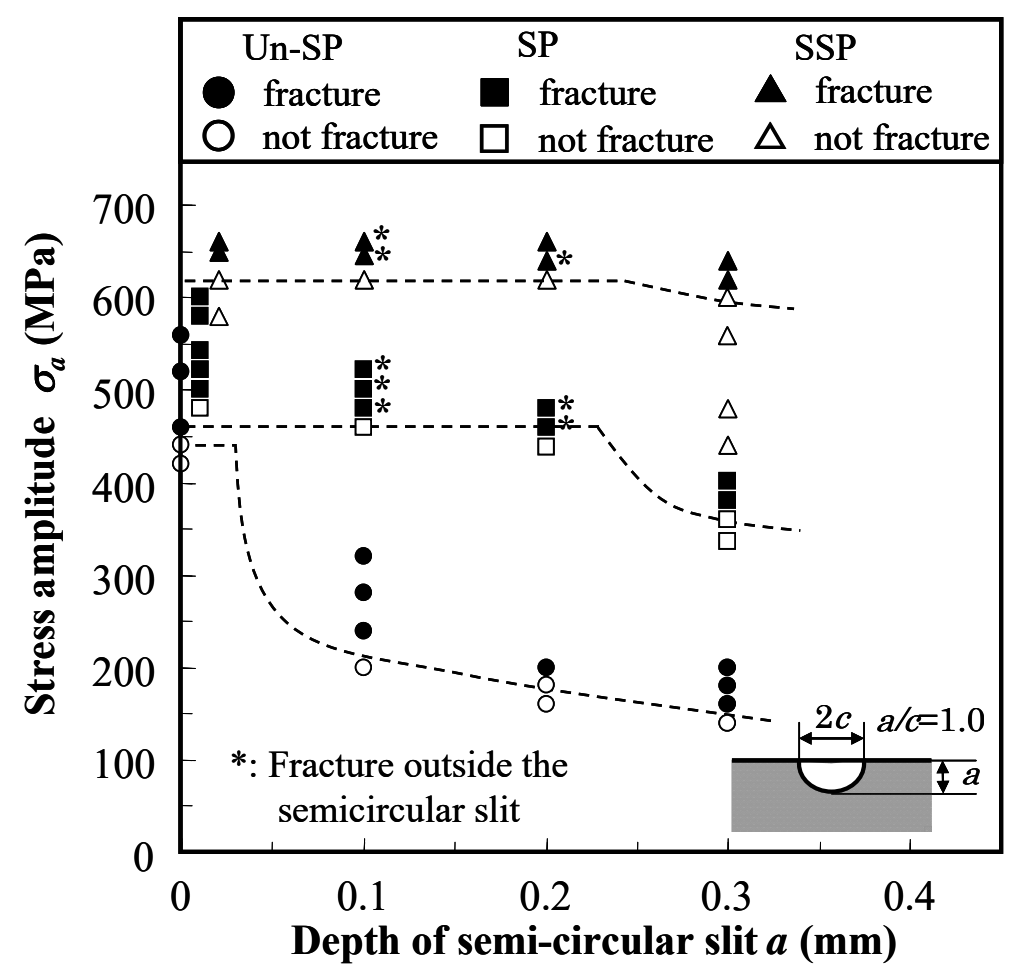

Fig.7 Relationship between stress amplitude and depth of semi-circular slit. 


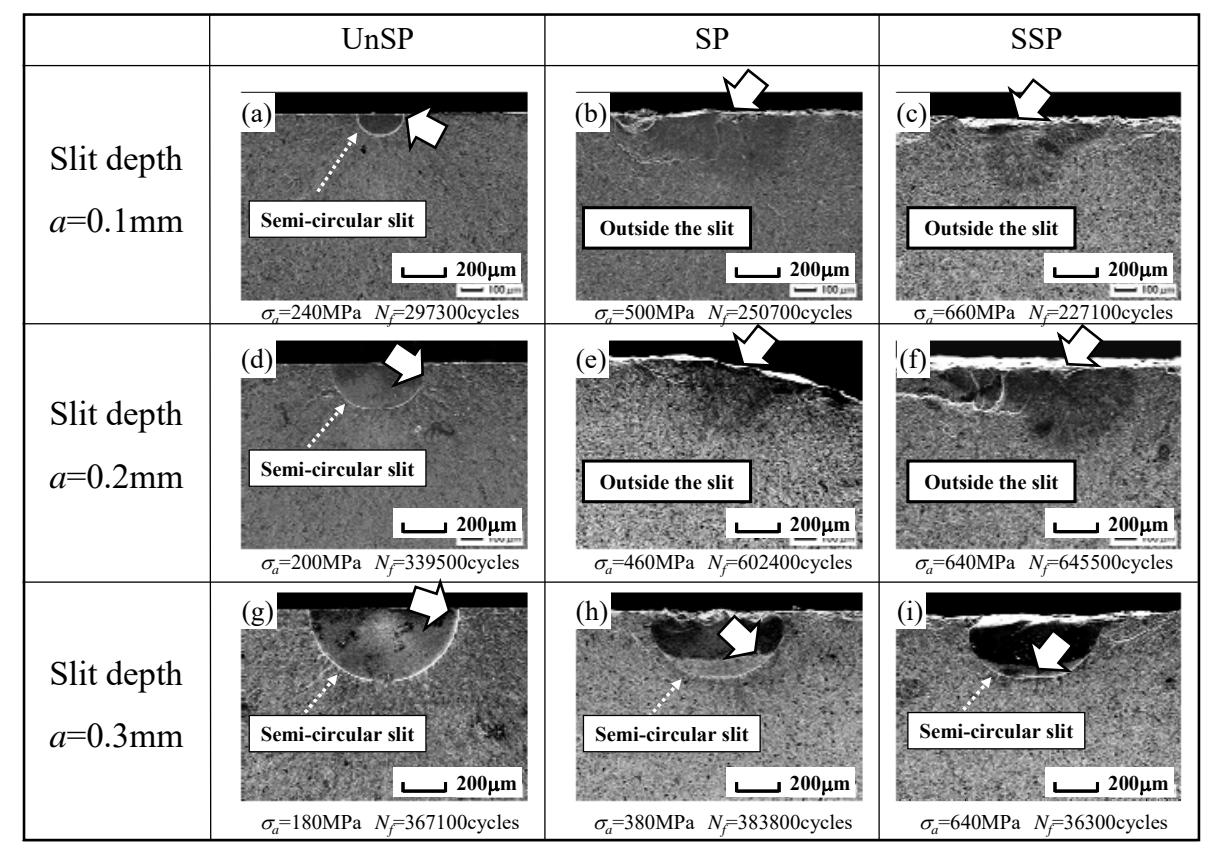

Fig.8 Fatigue fracture surface.

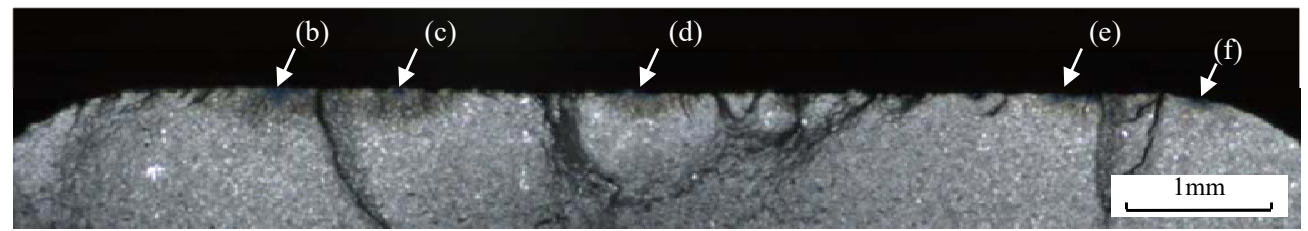

(a)

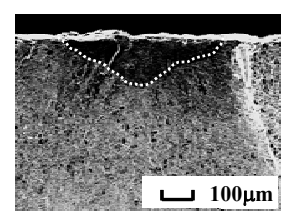

(b)

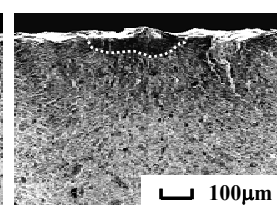

(c)

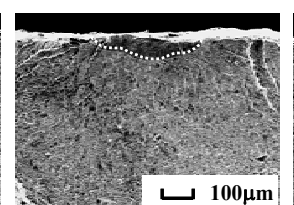

(d)

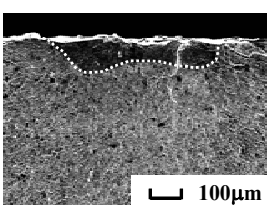

(e)

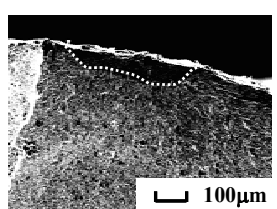

(f)

Fig.9 Non-propagating crack observed on the fracture surface of specimen tested under fatigue limit (slit depth $a=0.1 \mathrm{~mm}, \mathrm{SP}, \sigma_{a}=460 \mathrm{MPa}$, not fractured at $10^{7}$ cysles). (a) shows lower magnification of compulsory fractured surface after heat tint and $(b) \sim(f)$ shows higher magnification of (a). 


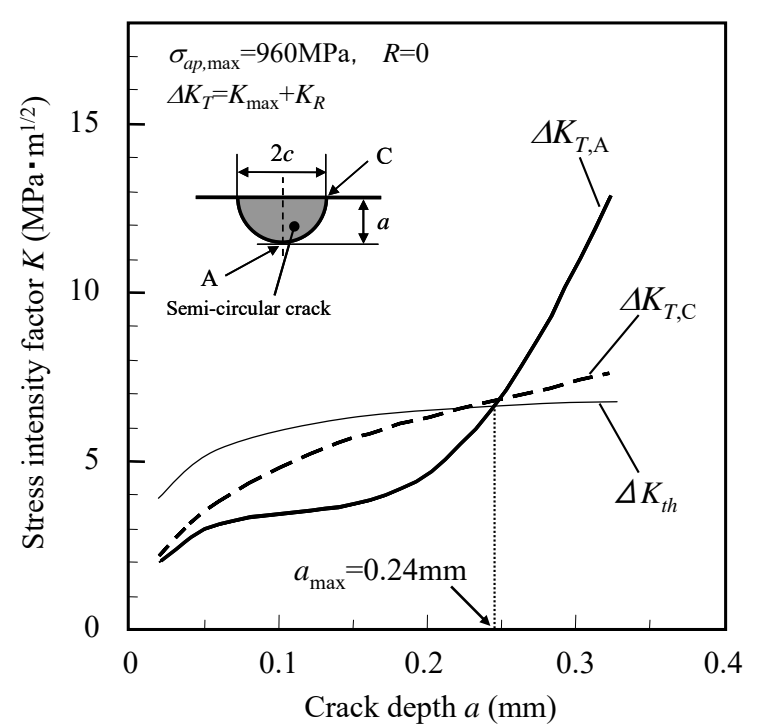

(a) SP specimen

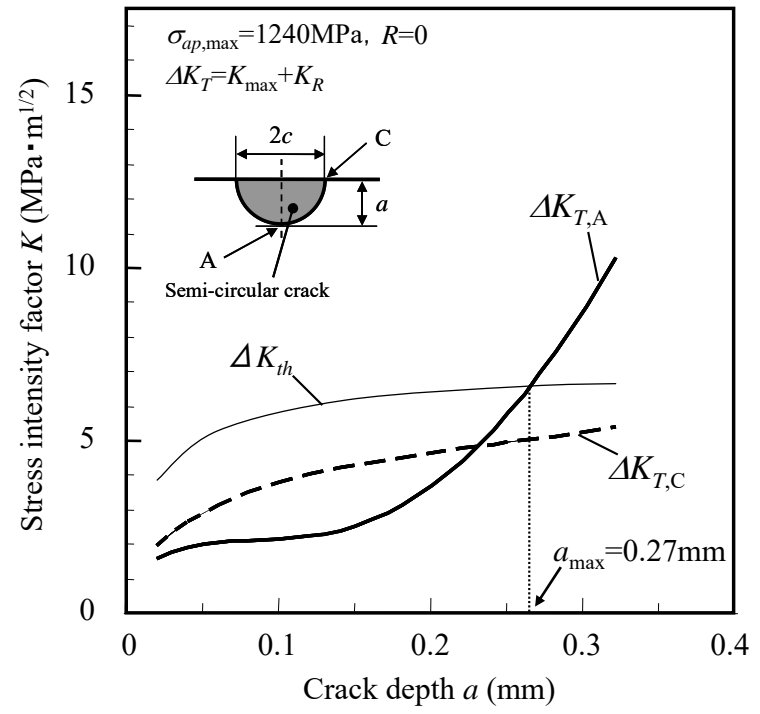

(b) SSP specimen

Fig.10 Estimation of the crack size rendered harmless by SP and SSP. 